\title{
Turismo sustentable para la Amazonia peruana
}

DOI:10.22403/UQROOMX/TYP05/18

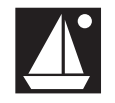

\section{Manuel González Herrera*}

\section{Resumen}

El artículo presenta los resultados de un estudio realizado en la provincia de Maynas, inserta en la Amazonia peruana, con el propósito de impulsar su posicionamiento como destino turístico amazónico ante los mercados emisores de selva. Se realiza desde la perspectiva de la gestión sostenible que demandan los espacios turísticos sensibles, desde la fase inicial de su desarrollo. Al respecto, se presenta una valoración del contexto del objeto de estudio, un diagnóstico de su potencial y las restricciones para su proyección como destino turístico. Finalmente, se formulan estrategias básicas para crear un sistema de turismo responsable.

Palabras |Amazonia peruana, desarrollo sostenible, gestión de destinos turís-

CLAVE ticos, modelo turístico, posicionamiento estratégico. 


\section{Introducción}

Para integrar modelos de desarrollo turístico sostenible en ambientes sensibles, es necesario transitar de la conceptualización de soluciones a las actuaciones preventivas. Bajo este paradigma, la gestión de los destinos turísticos contemporáneos deberá proyectarse sobre la base de la puesta en valor (mise en valeur) de los auténticos atractivos patrimoniales que caracterizan la identidad natural y cultural del ambiente local en el que se desarrolla el proceso de producción del espacio turístico. Los modelos de turismo tradicional están asociados a negativos impactos ambientales, sociales y económicos, lo cual indica la incompatibilidad de usos y funciones de proyectos de desarrollo turístico, disociados de su contexto.

La Amazonia peruana se ha convertido en un destino turístico de gran potencial, pero la diversificación de sus productos es aún incipiente así como su posicionamiento en mercados verdaderamente interesados en la realidad local. Al respecto, uno de los factores de mayor incidencia negativa es la falta de cultura turística de la población local, lo cual impide a los residentes integrarse conscientemente al turismo. Esa cultura fortalecería la dimensión ambiental en función de las particularidades del destino, en el que se combinan paisajes sensibles con alto grado de naturalidad y fortalezas étnico culturales de connotación exclusiva (González, 2000).

Es oportuno reconocer que esta falta de cultura turística está condicionada por el desconocimiento, tanto del turismo como fenómeno socioeconómico complejo como de las propiedades de la amazonia como sistema ambiental que soporta el desarrollo turístico; lo cual dificulta la comprensión de las relaciones funcionales entre los mercados de selva y los destinos amazónicos, en los que se dispone de un invaluable patrimonio natural y cultural como atractivo turístico.

Atendiendo estas consideraciones, el objetivo del presente trabajo es caracterizar la problemática del turismo en la provincia de Maynas, perteneciente a la Amazonia peruana, con el propósito de ubicarla en los mercados de selva como destino turístico. Con los resultados del estudio se pretende, además, comprometer a sus habitantes en acciones de gestión participativa para promover modelos de desarrollo sostenible. Esta visión de futuro requiere de una elevada cultura turística, fundamentada en el conocimiento de su medioambiente natural, social y económico. 


\section{Antecedentes y metodología}

La problemática del desarrollo del turismo sostenible en la Amazonia peruana ha sido objeto de atención científica nacional e internacional, especialmente para su preservación y uso racional. Organizaciones gubernamentales y no gubernamentales han desarrollado proyectos de investigación e intervención desde diversas perspectivas, que se incorporan en este trabajo; asimismo, se analizaron las actuaciones del sector turístico local, en las cuales se advierte la falta de transversalidad para la gestión con enfoque de destino.

A partir de la revisión bibliográfica y documental del tema, se establecieron los fundamentos teóricos y metodológicos de la investigación. Para caracterizar el área de estudio se levantó, además, información de campo.

Con el escenario obtenido, se realizó el diagnóstico de la problemática local del turismo mediante el análisis en pequeños grupos de discusión, entrevistas a informantes clave y encuestas, así como consultas con expertos, representantes de organizaciones sociales y del gobierno local. Finalmente, a partir de la interpretación de los resultados, se elaboró la proyección estratégica del destino, la cual fue validada en trabajo de taller con los sujetos implicados en el estudio y por el criterio de expertos por preferencia.

\section{Premisas teóricas}

El turismo constituye un fenómeno socioeconómico complejo que involucra múltiples relaciones funcionales vinculadas en forma directa e indirecta a diferentes esferas de la vida social, política y económica del escenario en que tiene lugar (González, 2006). En tal sentido, estas esferas deben ser consideradas en niveles equivalentes de significación, como premisa básica para la creación de modelos de desarrollo sostenible.

El uso de los recursos/atractivos que potencian el desarrollo de las actividades turístico-recreativas está condicionado por su valor patrimonial (Vidal, 2000). Es oportuno, por tanto, identificar con el término patrimonio turístico al conjunto de componentes y elementos naturales, histórico-culturales y socioproductivos, representativos de identidades pasadas y del presente, los cuales tenemos la responsabilidad de conservar para el disfrute espiritual de las generaciones actuales y futuras, ya que revelan los mecanismos de interacción entre la naturaleza y la sociedad en su decurso geohistórico. 
En este sentido, se estarán incorporando el patrimonio natural, el vivido y el construido por la sociedad, como fuente que potencia las actividades turístico-recreativas. No obstante, en la valorización del patrimonio suele existir una percepción contradictoria entre el visitante y el local, pues mientras el primero le reconoce una gran riqueza, el segundo, por serle cotidiano, no advierte ese valor intrínseco. Por lo tanto, se hace necesario priorizar los procesos educativos de los residentes locales en función de la valoración integral de su patrimonio. Esto permitirá potenciar el aprovechamiento y protección de los destinos turísticos sobre bases sostenibles, a la vez que promover el disfrute de los habitantes comprometidos con la idea de vivir en un espacio de alta significación, determinada por los atributos que le conceden valor de uso turístico a su lugar de residencia.

El análisis de la relación patrimonio-turismo presupone la incorporación de los valores naturales y culturales como objeto de interés cognoscitivo. Esto significa que en el proceso de consumo turístico, el patrimonio adquiere valor a partir de la experiencia del visitante durante el viaje y por los múltiples servicios generados en función de los propios valores inherentes al patrimonio de uso turístico.

Las ciudades, en particular, tanto históricas como modernas, asumen un rol protagónico en la producción de espacios turísticos. De hecho, turismo y ciudad han estado vinculados durante la historia de la humanidad. El proceso de formación y desarrollo turístico reconoce entre sus antecedentes el papel de las ciudades de la Antigüedad y la Edad Media en relación con los viajes como actividad, tendencia que tiene continuidad durante las épocas moderna y contemporánea al registrase un fuerte vínculo de las ciudades con diferentes modalidades turísticas.

Por tanto, el protagonismo de las ciudades permite advertir que el proceso de asimilación y desarrollo turístico urbano es responsabilidad política de la interacción entre actores múltiples, cuyos roles y responsabilidades dinamizan ese desarrollo sin interponer resistencias injustificadas, premisa de notable connotación para nuestros días en que el proceso de producción del espacio urbano se caracteriza por un gran dinamismo, alta densidad constructiva y fuertes demandas de servicios básicos.

La ciudad es, entonces, un espacio erigido por el hombre, que funciona por las interacciones socioculturales y económicas practicadas por la sociedad en 
un ambiente físico particular. Es, por tanto, un sistema ambiental de carácter abierto, múltiple y complejo, el cual se desarrolla sobre un fondo natural que se refleja en su fisonomía y funcionalidad, a la vez que pone de manifiesto una diferenciación espacial interna con tendencia a la fragmentación y especialización, a partir de lo cual está mediada por un conjunto de actores sociales y agentes económicos que regulan su funcionamiento: el gobierno local, las empresas del sector público y privado, las instituciones sociales y culturales, la comunidad con sus individuos, entre otros.

Así, se puede afirmar que el papel de las ciudades como actores del desarrollo turístico y su liderazgo creciente en los nuevos modelos de desarrollo -acorde con las tendencias y comportamientos del mercado- posicionan en el centro del debate profesional, e incluso popular, el tema relativo a las múltiples relaciones entre la ciudad y el turismo. De lo anterior se desprende que constituye una prioridad la búsqueda de criterios de sostenibilidad para la puesta en valor turístico del patrimonio natural y cultural de las ciudades amazónicas, para garantizar una gestión óptima de los impactos resultantes de las funciones turístico recreativas que implican a los espacios naturales, rurales y urbanos de la Amazonia; máxime, que los destinos turísticos basados en modelos tradicionales de desarrollo reportan elevados niveles de deterioro.

Se impone como una de las necesidades más impostergables para la sociedad contemporánea sustentar procesos de formación y desarrollo de los nuevos destinos turísticos bajo los enfoques de la planificación, diseño y gestión sostenible. Esta premisa debe ser básicamente orientadora para los nuevos espacios naturales e histórico-culturales con vocación turística (Croall, I995:I80).

\section{Contexto geoespacial de la Amazonia peruana}

El espacio geográfico amazónico está constituido por uno de los sistemas ambientales de vida natural más extenso, complejo y diverso de nuestro planeta. Sus condiciones ambientales y la conformación progresiva de una base técnicoeconómica han promovido la asimilación turística como actividad alternativa estratégica para el desarrollo socioproductivo endógeno (González, 200 I).

En el territorio que ocupa la Amazonia peruana se ubica la municipalidad provincial de Maynas, la más extensa del departamento de Loreto, con una 
superficie de 1 I $9859 \mathrm{~km}^{2}$ (INEI, 2003). El área geográfica de la cual forma parte genera un potencial que permitirá conformar un producto turístico de gran atracción, dadas sus caracterísicas físico-geográficas y socioculturales, las cuales reúnen recursos turísticos de una notable belleza escénica.

El espacio amazónico de la provincia de Maynas tiene un relieve llano y suavemente ondulado con impresionantes formas fluviales, entre las que sobresale el espectacular valle del Amazonas. De clima ecuatorial. con temperatura media anual de $22{ }^{\circ} \mathrm{C}$ y una variabilidad anual que oscila entre el promedio mínimo de $19{ }^{\circ} \mathrm{C}$ en el mes más fresco y el máximo con $35^{\circ} \mathrm{C}$ en el mes más cálido. Las precipitaciones son abundantes durante todo el año, con volúmenes medios de 2000 a $3000 \mathrm{~mm}$, cuya distribución marca un período más lluvioso de diciembre a mayo y uno menos lluvioso de junio a enero. La humedad relativa es elevada, con valor aproximado de ochenta y cuatro por ciento.

Uno de sus atractivos geoespaciales más relevantes es el sistema hidrográfico del Amazonas, el mayor de nuestro planeta. En el período de enero a mayo (invierno), el río alcanza 1 I 7 msnm, y desciende 1 I 0 msnm en la temporada de julio a diciembre (verano). Esta fluctuación se hace evidente en el paisaje y en la vida del habitante amazónico, lo que constituye un verdadero atractivo para el visitante.

Otro elemento de gran singularidad es la diversidad de flora y fauna silvestre; destacan plantas y animales exóticos, especies endémicas y raras, con rango de distribución restringida, así como valiosos árboles medicinales, maderables y frutales de reconocido valor mundial. En particular, resulta interesante la extraordinaria riqueza de vida acuática y ribereña, base alimentaria de la población local.

La selva amazónica se caracteriza además por disponer de áreas de deforestación mínima.Atrae poderosamente la atención del visitante la composición y la estructura de los bosques, en los que es frecuente la presencia de árboles gigantes y elementos carismáticos de la flora y la fauna, como: aguajes, árbol cumaceba, lirio acuático, pirañas, charapas y taricayas, delfines grises y rosados, paiches, manatíes, vacas marinas, lagartos y caimanes, anacondas, monos, perezosos, jaguares, tapires, guacamayos y loros, mariposas e insectos, entre otros.

La población local es en sí misma un importante atractivo turístico. La provincia tiene 523289 habitantes (INEI, 2003), desigualmente distribuidos y socialmente diferenciados. Predomina una población mestiza no nativa, influenciada durante diferentes momentos históricos por oleadas migratorias procedentes del 
extranjero, de la propia sierra y de la costa peruana. La población urbana es superior a la rural, fenómeno que tiende a incrementarse con las migraciones sucesivas del campo a la ciudad. Es importante resaltar que en Loreto, aproximadamente ocho por ciento de la población es nativa, y de ésta poco más de cuarenta por ciento se dedica al campo; esto indica la gran cantidad de oportunidades que existen para visitar comunidades amazónicas en las que es posible disfrutar de fiestas típicas, danzas, artesanías, etcétera.

Las actividades económicas tradicionales corresponden a la agricultura migratoria, la caza, la pesca y la recolección. Este modelo económico de autosubsistencia y extracción de recursos naturales es representativo de la cultura prehispánica, por lo que en ocasiones se convierte en motivo de visita. Sin embargo resulta obsoleto, lo cual acentúa los niveles de pobreza que caracterizan la realidad de estos pueblos.

\section{Ciudades amazónicas peruanas como agentes protagónicos del turismo: Iquitos}

El tema de la participación de las ciudades amazónicas peruanas en el turismo resulta de gran importancia y actualidad, debido a su rol como agentes dinamizadores de los desarrollos turísticos y su incidencia protagónica cada vez mayor en la conformación de nuevos modelos de desarrollo, vinculados a los espacios naturales y rurales en los que se insertan. En tal sentido, la ciudad se convierte en un agente político para el turismo (Arcarons y Datzira, 2005) por el papel que se le adjudica al poner en acción a los sujetos conscientes de una política con la cual se comprometen frente al desarrollo turístico.

Otro atributo de las ciudades amazónicas peruanas se asocia con los procesos naturales y culturales con los cuales se les identifica. En estos espacios, el motivo fundamental de viaje está relacionado con atractivos de la selva; paradójicamente, la propia ciudad y la población local suelen quedar excluidas de la oferta turística. Este enfoque minimiza el rico valor complementario del paisaje urbano al dejar fuera del consumo turístico un apreciable conjunto de bienes públicos y privados que pudieran reforzar el disfrute y satisfacción de los visitantes y beneficiar al residente local.

El debate relativo al protagonismo de las ciudades amazónicas frente a los nuevos desarrollos turísticos debe ser orientado en correspondencia con una 
reconceptualización del turismo cultural como producto turístico, debido a que pone en evidencia la cultura material y espiritual de la sociedad en su decursar histórico y localización geográfica definida. Como conjunto de exponentes de las actividades desarrolladas por el hombre, los espacios turísticos culturales más reconocidos son precisamente urbanos, aunque en la actualidad se manifiesta un interés hacia ámbitos naturales y rurales dotados de elementos que nos documentan acerca de las formas en que diferentes grupos sociales se han relacionado con su ambiente en momentos históricos y lugares diversos.

La motivación del turismo cultural en las ciudades amazónicas se basa en el deseo por conocer y experimentar emociones durante la visita a extensos espacios naturales con valores patrimoniales, en los cuales, a la vez que el turista aprende y disfruta, se educa desde el punto de vista histórico, cultural, científico, estético, pero singularmente y por encima de todo, humano. Esta motivación se inspira en el deseo de encontrar información que amplíe su horizonte cultural, así como de experimentar emociones que lo enriquezcan en el orden espiritual durante su contacto vivencial con los destinos amazónicos. El segmento de turismo especializado en este producto puede entrar en contacto con la cultura ancestral, exponente de las costumbres, tradiciones, modos de vida, creaciones artísticas y literarias que le confieren un sentido particular a cada una de estas ciudades, que se convierten así en parte de la experiencia turística.

Al abordar el tema de las ciudades amazónicas peruanas como actores políticos es necesario enfatizar que la gestión del patrimonio cultural de estas localidades deberá tomar en consideración, como acciones imprescindibles para promover un turismo responsable, la capacidad de carga turística, el control de los flujos de llegadas y el respeto entre visitantes y residentes. En esta dirección es importante el papel de los medios de comunicación social como promotores de una cultura popular protagonizada por la comunidad. De esta forma, se estarán estableciendo las bases que permitirán maximizar los impactos positivos que puede generar el turismo en las diferentes facetas de la vida cultural, material y espiritual de la sociedad.

Las administraciones locales y demás actores políticos deberán fundamentar su gestión en políticas trísticas coherentes con la problemática real del ambiente urbano, la cual regularmente está caracterizada por escasez relativa de alimentos y artículos de primera necesidad para una parte importante de la sociedad; insuficiente saneamiento ambiental; baja habitabilidad de las viviendas en determinadas 
áreas de la ciudad; transporte público insuficiente e inadecuado; combustible doméstico escaso; mal estado de las redes hidrosanitarias; deformación entre la identidad de la ciudad y la imagen percibida, entre muchas otras situaciones de deterioro, expresadas en bajos niveles de calidad de vida.

Por tal motivo, para dirigir la práctica del turismo tradicional hacia el mejoramiento de la calidad de vida del habitante amazónico, la primera responsabilidad política de la administración debe ser la formación de una cultura integral en los residentes locales. La gestión urbana mediante proyectos comunitarios con sujetos capacitados puede contribuir a elevar las condiciones de las viviendas; al desarrollo económico local autogestionado y participativo; mejorar la educación urbana básica e identidad barrial; en la higienización y saneamiento ambiental; arborización y creación de espacios públicos y de áreas verdes urbanas; atención priorizada a los estados de opinión, necesidades básicas y oportunidades de participación ciudadana, y a mecanismos de financiación local de la ciudad como destino turístico. Una importante línea de las políticas turísticas debe orientarse a la puesta en valor de los centros históricos, evitando la masificación de los espacios más simbólicos, a la vez que se conforma una oferta cultural autóctona y se posiciona el producto a partir de la promoción de eventos y ferias que revaloren al habitante amazónico y su hábitat.

lquitos, capital de la municipalidad provincial de Maynas y del departamento de Loreto se abre al turismo como puerta de entrada a la Amazonia peruana, por constituir su principal puerto fluvial, y destino aéreo potencial desde cualquier parte del mundo. Esta ciudad selvática situada a poco menos de cuatro grados de latitud sur, en las proximidades del Amazonas, y a una altitud de II 2 msnm, encierra el misterio y el encanto del ambiente que la vio surgir.

La ciudad fue fundada en I864, aunque su colonización se produjo décadas antes. Su urbanización es resultado de un crecimiento espontáneo e inorgánico, caracterizado por la expansión en el eje norte-sur.Su desarrollo ha estado marcado por diferentes acontecimientos históricos, como el boom del caucho de 1880 a 1914 y, más recientemente, en los años 60 , el del petróleo y del narcotráfico. Eventos históricos sucesivos se manifiestan en la arquitectura, la trama urbana, la identidad cultural formada a partir del encuentro entre varias culturas y las particularidades demográficas.

En la actualidad, esta ciudad presenta condiciones de vida que expresan señaladas diferencias socioespaciales con precarios asentamientos humanos peri- 
féricos y problemas ambientales propios de las ciudades interiores de los países subdesarrollados. Su economía urbana es comercial y de servicios, en la que ocupan un importante lugar los establecimientos de hospedaje y restaurantes para consolidar la oferta turística.

\section{Potencial y restricciones para el posicionamiento turístico de Maynas}

El análisis de los valores ambientales de la provincia de Maynas permite identificar los siguientes factores potenciadores para el desarrollo turístico:

- Situación geográfica en el corazón de la Amazonia peruana y su proximidad al río más caudaloso del mundo

- Peculiaridad de su clima ecuatorial, cálido y lluvioso

- Abundancia de cuerpos de agua, como ríos selváticos, cochas y quebradas, los cuales generan un alto potencial de recursos hídricos

- Biodiversidad y diversidad paisajística con una marcada aptitud forestal

- Estado de conservación natural en ambientes casi inexplorados y alejados de la "civilización", con variados colores, sonidos y olores naturales

- Cultura del hombre amazónico vinculada al ambiente fluvial

- Hospitalidad y sencillez de la población local

- Comunidades indígenas y mestizas, con diversidad étnica y lingüística

- Heterogeneidad cultural y preservación de tradiciones ancestrales

- Interesante historia natural y sociocultural, con sitios arqueológicos, antropológicos, etc., de valor patrimonial

- Riqueza gastronómica y conservación de tradiciones culinarias representadas por platillos y bebidas típicas

- Tecnologías nativas y modelos productivos tradicionales

- Disposición del sector privado para la inversión local

- Capacidad hotelera y extrahotelera instalada

- Incorporación del turismo como objeto de estudio y asimilación de su problemática ambiental como objeto de investigación

- Voluntad política para potenciar el desarrollo turístico 
Al mismo tiempo, es necesario reconocer oportunamente los factores limitantes para el desarrollo del turismo en la provincia de Maynas, para minimizar sus incidencias adversas:

- Insuficiente disponibilidad y mecanismos para la implementación de marcos legales y normativos relativos al turismo, así como de las competencias institucionales

- Incapacidad administrativa para la gestión y manejo racional de los recursos naturales que sustentan el desarrollo turístico

- Regulación del turismo sobre la base de los límites de capacidad de carga y del uso no comercial de la naturaleza (maderas, animales, huesos, pieles, etcétera)

- Falta de cultura turística general en las comunidades anfitrionas e incapacidad para valorar el patrimonio turístico natural y cultural

- Falta de educación especializada, básica en las diferentes áreas operativas del turismo

- Falta de guías oficiales de turismo formados y especializados

- Falta de educación turística orientada al consumidor

- Limitada integración de las comunidades locales al turismo

- Niveles de pobreza e incremento de los índices de delincuencia

- Riesgos para la salud por causa de la malaria, fiebre amarilla y mordedura de serpientes venenosas, entre otros

- Difícil acceso a distintos lugares de interés turístico

- Escasos estudios científicos y puntuales, lo cual genera cierto déficit de información

- Falta de viabilidad para la inversión turística local del sector privado

- Limitada competitividad frente a otros destinos turísticos emergentes de selva

Tomando en consideración la dinámica actual del turismo, el posicionamiento de la provincia de Maynas como destino amazónico requiere del desarrollo y consolidación de los siguientes polos de atracción turístico-recreativa:

- Corredor turístico del Amazonas. Este majestuoso río está identificado en el Plan Maestro de Desarrollo Turístico del Perú por sus numerosos atractivos. 
Permite conocer el nacimiento del Amazonas en la confluencia de los ríos Marañón y Ucayali, visitar comunidades rurales nativas y mestizas, áreas naturales y urbanas. Son de particular interés las playas fluviales relacionadas con este sistema hidrográfico, las cuales aparecen en julio, agosto y septiembre; entre las más conocidas están las playas del Nanay y del Itaya.

- Ciudad de Iquitos. Ofrece lugares interesantes entre los que destaca el barrio flotante de Belén, conocido como la Venecia selvática,y el malecón Tarapaca, en el centro urbano histórico, con valiosas construcciones del siglo XIX, el Museo Amazónico, la Biblioteca Amazónica, la Galería de Arte $y$, por sobre todo, la vida cultural de esta ciudad.

- Ruta lquitos-Nauta. Esta joven arteria vial enlaza dos importantes ciudades amazónicas. Requiere del desarrollo de nuevos atractivos pero los ya existentes acaparan la atención del visitante, como es el caso del Parque Turístico Quistococha; a la vez, ofrece acceso a otros centros de interés turístico. Su potencial como vial escénico integra un conjunto variado de incentivos cognoscitivos y estéticos que permiten acercarse a la realidad amazónica, como es el caso de las piscigranjas.

- Comunidades nativas indígenas. Constituyen un elemento emblemático para el etnoturismo. Permiten conocer la diversidad étnica, ritos, modos de vida y costumbres autóctonas. Entre las numerosas comunidades puede citarse a los boras, jíbaros y yaguas.

- Comunidades rurales. Se caracterizan por la práctica de actividades socioproductivas tradicionales y el desarrollo cultural vinculado al espacio rural. Entre los caseríos campesinos se encuentran las comunidades Veinte de Enero, Yarina y la cocha El Dorado.

- Reservas naturales. Están integradas por áreas de alto valor natural y cultural, en un espacio donde predomina la naturaleza, y la historia es latente. Su riqueza singular ha motivado medidas especiales de manejo, orientadas a la conservación integral y mejoramiento sostenido.Además de su interés para los visitantes foráneos, ofrecen magníficas oportunidades para el turismo local y la educación ambiental. 
Sobresale por su significación para el desarrollo turístico la Reserva Nacional Pacaya Samiria, área protegida más grande del Perú, con una superficie de 2080000 hectáreas. Corresponde a una llanura aluvial de selva baja que discurre entre los ríos Marañón y Ucayali hasta su confluencia en las proximidades de Nauta, donde se localiza el nacimiento del Amazonas. Se trata de la zona protegida de bosques inundables o varzea más extensa de la Amazonia, donde naturaleza y comunidades nativas indígenas y mestizas se integran conformando un ambiente único de extraordinaria riqueza biológica y humana. Por otro lado, resulta de interés la zona reservada Allpahuayo-Mishana ubicada en las proximidades de Iquitos, que corresponde a bosques sobre arenas blancas con una gran biodiversidad y exclusividad de animales y plantas. Es también de gran importancia para potenciar el turismo la Reserva Comunal Tamshiyacu-Tahuayo por su fácil accesibilidad desde lquitos y la gran riqueza de fauna silvestre.

La puesta en valor de los atractivos turísticos disponibles en las áreas de mayor significación para la provincia de Maynas posibilitará la elaboración de un producto amazónico especializado en las siguientes modalidades de turismo: ecológico, sociocultural, rural, de aventura, de crucero fluvial, científico y escolar.

Estos segmentos turísticos se desarrollarán en correspondencia con la tipología y características ambientales de mayores fortalezas y oportunidades para su consolidación como producto turístico (Comité Consultor de Turismo de Loreto, 200 I). Al respecto, resulta de gran importancia para su posicionamiento exitoso la diferenciación que alcance la oferta frente a otros destinos turísticos emergentes de selva.

Se encuentran en proceso de formación la infraestructura y los servicios turísticos. En esta etapa la planta hotelera incorpora más de 400 empresas que ofrecen servicios de alojamiento y alimentación, entretenimiento, transportación, viajes turísticos y otras ofertas complementarias. Uno de los elementos más importante de esta oferta corresponde a los establecimientos de hospedaje: hoteles y hostales, albergues de selva y establecimientos no clasificados y no categorizados. Los albergues de selva han sido diseñados como cabañas turísticas integradas al ambiente natural, ejemplos de esta clase son $\mathrm{Cu}-$ maceba Lodge, Amazon Rainforest Lodge y Bombanaje Camp.

Predominan los establecimientos no clasificados y no categorizados, con la mayor utilización de la capacidad instalada; se ubican en segundo término, los 
albergues de selva y los hostales tres estrellas. Elementos distintivos de la oferta de transporte turístico son los típicos motocars, que colman la ciudad, y las embarcaciones del tipo peque-peque y pacamari.

La demanda turística se ha caracterizado por un crecimiento sostenido (Comité Consultor de Turismo de Loreto, 200I). Refleja una tendencia preferencial de intereses generales, más que especializados, aunque con orientación hacia la naturaleza. En tal sentido, los lugares de atracción turística más frecuentados son la selva, preferentemente conservada, y las comunidades nativas; mientras que la propia ciudad de lquitos generalmente queda fuera de comercialización. Algunas de las actividades turísticas más demandadas son: expediciones a la selva primaria para observar la flora y la fauna; la fotografía de naturaleza; aventura y cursos básicos de supervivencia en la selva; excursiones por el Amazonas para disfrutar del ambiente acuático y ribereño; pesca fluvial artesanal, ski acuático, actividades de canotaje fluvial, natación, etc.; visita a comunidades rurales nativas y mestizas; celebración de festividades locales, como la Semana Turística de lquitos, que genera una gran demanda, y estudios e investigaciones científicas de la naturaleza y la sociedad autóctona.

Para atender esta demanda se organizan circuitos fluviales por el Amazonas y sus principales afluentes, los cuales incorporan elementos de gran atracción, como el pasadizo colgante sobre un afluente del Napo o el recorrido por el Nanay, único río conocido de lgapó o bosque inundable de aguas negras. Asimismo, se organizan circuitos de turismo especializado y de aventura, los cuales utilizan trochas a través del bosque para realizar las caminatas y embarcaciones típicas para pasar pequeños cuerpos de agua. En algunas de estas travesías es posible encontrar árboles de caucho que conservan las marcas de su antigua explotación.

La ciudad de lquitos registra un arribo anual superior a 88000 visitantes. En cuanto a su procedencia, los mercados emisores nacionales cubren aproximadamente $60 \%$ del flujo total de visitantes, indicador en el que destaca la ciudad de Lima. El turismo receptivo extranjero procede mayoritariamente de los Estados Unidos, seguido de países europeos como Francia, Reino Unido, Alemania y España.

El comportamiento estacional de la afluencia turística registra mayor incidencia de visitantes nacionales en los meses de enero y febrero, en tanto que en junio y julio ocurre el mayor arribo de turistas extranjeros.A su vez, se 
reporta mayo como el mes de menos llegadas nacionales, y abril el de menor afluencia extranjera. Otro indicador importante de la demanda turística es el bajo número de pernoctaciones en este destino.

Los canales de promoción turística están representados por las agencias de viaje receptoras, que en su mayoría disponen de oficinas en Lima, así como por diferentes touroperadores. También empiezan a usar medios no convencionales, como los sistemas de Información Turística e Internet. Promperú ha establecido un plan de marketing basado en la diversidad temática para facilitar el multidestino en función de las motivaciones de los segmentos turísticos potenciales; por su parte, la Oficina de Información Turística de la provincia de Maynas distribuye en sitios estratégicos carpetas con folletos y fotografías sobre la oferta turística.

En relación con las iniciativas de promover prácticas ambientales responsables, es oportuno implementar mecanismos de control para hacerlas cumplir por quienes gestionan las actividades turísticas y, a la vez, hacer que la población local y los visitantes las asuman como parte de la experiencia que propicia la interacción con este importante sistema ambiental (Haulot, 1991: I 82). Para la integración de las comunidades locales al turismo se instrumentan iniciativas como el proyecto Rumbo al Dorado, basado en una experiencia de trabajo comunitario, o el proyecto de Manejo de la Fauna Silvestre, con la colaboración de las comunidades locales en la reserva comunal Tamshiyacu-Tahuayo.

Hasta el momento, el contacto entre la población local y los turistas en la provincia de Maynas es limitado, espontáneo y sin un propósito claramente definido. Este escenario requiere de un turismo con protagonismo local participativo, proceso en el cual se hace evidente la falta de cultura turística y la insuficiencia de códigos de comportamiento turístico con dimensión ambiental.

Tomando como precedente el análisis hasta aquí planteado se puede concluir que la situación del turismo en la Provincia de Maynas está caracterizada por los siguientes problemas estratégicos:

- Pobre integración del patrimonio natural y cultural a la dimensión del espacio turístico como sistema ambiental

- Deterioro de la calidad ambiental en lquitos y localidades diversas por la deforestación y el manejo irracional de los recursos naturales

- Imagen turística convencional y algo alejada de la realidad amazónica 
- Pobre diversificación y diferenciación del producto turístico amazónico

- Concentración de la oferta turística en lquitos y elevada informalidad

- Planta turística convencional, manipulada y repetitiva

- Predominio de establecimientos turísticos no clasificados y no categorizados

- Baja ocupación y permanencia en establecimientos de hospedaje

- Amenazas ocasionales a la seguridad del turista

- Alto costo de los viajes en relación con la calidad de los servicios

- Baja demanda en segmentos turísticos especializados

- Presencia de algunos guías turísticos informales y sin licencia

- Comunidades locales pobremente identificadas con el turismo participativo

- Transculturación de las comunidades locales

- Extinción y peligro de desaparición de familias lingüísticas

- Modelos de desarrollo local basado en el turismo pasivo

- Beneficios económicos de limitada retribución en la calidad de vida de la población local

- Insuficiente promoción turística para la comercialización y operación turística

- Déficit de cobertura sanitaria y de áreas verdes

- Suministro insuficiente de agua a las instalaciones turísticas

- Deficiente sistema de suministro electroenergético y de telecomunicaciones

- Falta de ordenamiento en el transporte urbano y funcionalidad de la red comercial

- Insuficiente red vial entre centros de interés turístico, déficit de infraestructura portuaria y falta de capacidad para vuelos aéreos directos desde el exterior

- Deficiente calidad en los servicios de transporte terrestre y fluvial

- Insuficiente cobertura formativa de la cultura turística general y especializada 
Ante las restricciones y los problemas relativos al turismo planteados resulta sugerente la interrogante ¿qué hacer para lograr la excelencia en el sector turístico local? Con seguridad será oportuno definir la visión de futuro en diferentes horizontes temporales y en función de ésta redimensionar la misión con la que deben comprometerse cada uno de los actores sociales relacionados de una forma u otra con el desarrollo del turismo en la provincia de Maynas.

\section{Estrategias básicas para crear un modelo turístico de desarrollo sostenible}

Los retos para avanzar hacia un desarrollo turístico sostenible deberán focalizar, bajo el criterio de una estrategia participativa integrada, las principales esferas de actuación dentro del sistema turístico, lo cual permitirá promover proyectos para el desarrollo social (Cembranos, Montesinos y Bustelo, 200 I:240). Como marco para la elaboración de un Sistema de Turismo Responsable (STR) es recomendable trabajar en las siguientes direcciones estratégicas, comprometidas con la solución de la problemática que enfrenta el escenario turístico:

- Perfeccionamiento de las bases legales e institucionales para crear un ordenamiento jurídico normativo integral, sistémico, homogéneo y armónico, en materia de turismo y medioambiente, tanto para el sector público como privado. De esta forma será posible cubrir los vacíos de información y el déficit de mecanismos para su implementación práctica.

- Incorporar la planificación y el diseño ambiental, fundamentados en los criterios del espacio turístico como sistema ambiental, con vistas a lograr la compatibilidad respecto al medioambiente de los nuevos desarrollos y el reordenamiento de los ya existentes. Ello permitirá regular las interacciones entre la naturaleza y la sociedad tomando como base la incorporación del paradigma de desarrollo sostenible como premisa para minimizar impactos ambientales.

- Revalorización holística de las combinaciones entre recursos naturales, histórico-culturales y socioeconómicos disponibles, para su puesta en valor como atractivos turísticos frente a los mercados más exigentes. Con este propósito es conveniente disponer en la provincia de Maynas 
de una tipología y regionalización del patrimonio turístico que refleje las diferencias socioespaciales y el potencial de uso turístico, contextualizado bajo el enfoque de la representatividad de cada lugar.

- Conservación y mejoramiento permanente del patrimonio turístico natural y cultural que caracteriza la situación ambiental, apoyado en el fortalecimiento del proceso de su apreciación y valoración por todos los actores sociales que participen en este escenario. En particular, deberá comprometerse a las personas facultadas para la toma de decisiones, a los empresarios turísticos, gobiernos locales, líderes comunitarios, instituciones sociales, empresas de proyecto y de la construcción.

- Ampliación y mejoramiento de la planta turística y de los servicios directos e indirectos que distinguen a la provincia de Maynas como destino amazónico que produce una oferta de selva. Al respecto, deberá darse prioridad a la formalización de la micro y pequeña empresa turística, así como a la operación de touroperadores y guías turísticos.

- Consolidación de la imagen turística de la ciudad de lquitos, basada en criterios estéticos y ambientales atribuibles a la identidad local, para convertirla en destino amazónico obligado en el contexto de la selva peruana. En este sentido, las operaciones turísticas podrán incorporar circuitos turísticos urbanos de motivaciones histórico-culturales.

- Investigación de nuevos productos amazónicos y modalidades turísticas para diversificar y diferenciar la oferta potencial en el orden temático y en el ámbito geográfico. En función de ello podrán planificarse nuevos circuitos turísticos vinculados al ambiente natural y rural.

- Identificación de nuevos mercados turísticos de selva orientados hacia la naturaleza y las culturas indígenas, en el contexto nacional e internacional. La identificación de la demanda potencial permitirá mantener un crecimiento sostenido de las inversiones, de los arribos turísticos, del uso de la capacidad hotelera instalada y de los ingresos.

- Perfeccionamiento de la gestión administrativa en el sector turístico, centrada en la dimensión ambiental del marketing turístico y la consolidación de las relaciones públicas como sello distintivo en la identidad del producto turístico de la provincia de Maynas. 
- Incremento en cualitativo y cuantitativo de fuentes de información para garantizar la promoción y comercialización del producto turístico amazónico con efecto multiplicador, apoyado en canales de distribución no convencionales.Al respecto, deberán programarse con mayor frecuencia eventos y actividades socioculturales autóctonas.

- Implementación de mecanismos eficientes que promuevan la integración participativa de las comunidades al turismo, como alternativa de desarrollo endógeno y estímulo para compulsar la población local hacia la práctica de un turismo activo. Lo anterior dará una medida de la relación entre calidad de vida de la población anfitriona y turismo receptivo.

- Atención permanente al factor humano en el turismo, como vía para potenciar el capital humano local y evitar insatisfacciones en las experiencias del visitante. Oportunamente, deben ser orientados los procesos de comunicación entre el turista y el habitante amazónico para evitar conflictos sociales.

- Perfeccionamiento de los sistemas educativos curriculares y extracurriculares dirigidos a la formación de una cultura turística general en la población local,y la especialización de técnicos y profesionales del ramo a fin de garantizar la práctica de un turismo responsable, fortalecido en la dimensión ambiental.A su vez, deberá incentivarse el papel de los medios de comunicación en relación con la educación turística y ambiental.

\section{Conclusiones}

Resulta conveniente enfatizar la importancia de promover nuevos modelos turísticos, basados en los enfoques del desarrollo sostenible como alternativa para minimizar los impactos adversos generados por modelos convencionales y repetitivos que ponen en peligro los atractivos del potencial natural e histórico-cultural, que condiciona la propia formación y desarrollo de cada destino turístico.

La puesta en valor turístico del alto potencial de la Amazonia peruana está marcada por la la falta de cultura turística en la población local para integrarse conscientemente a un turismo con dimensión ambiental. Este espacio demanda estrategias de intervención participativa que involucren a todos los actores 
sociales implicados con el desarrollo turístico, dadas las características de este destino, en el que se combinan paisajes sensibles con alto grado de naturalidad y fortalezas étnico-culturales de connotación exclusiva.

En este sentido, la problemática actual del turismo en la provincia de Maynas expone los factores potenciadores y las limitantes para promover su posicionamiento como destino turístico amazónico frente a los mercados de selva. Con el propósito de alcanzar esta imagen de destino será necesario comprometer a los habitantes amazónicos con acciones de autogestión turística para impulsar modelos de desarrollo sostenible que permitan valorizar en toda su magnitud el patrimonio de uso turístico, tanto para el disfrute del visitante como para el residente de este singular destino.

\section{FUENTES CONSULTADAS}

Arcarons, Ramón y Jordi Datzira (2005). Los destinos turísticos locales. Singularidad en la gestión [en línea]. Material didáctico. Máster en Gestión de Destinos Turísticos Locales. Grupo CETT. Barcelona: Universidad de Barcelona. Disponible en: http:// www.cett.es

Cembranos, Fernando, David Montesinos y María Bustelo (200I). La animación sociocultural: Una propuesta metodológica, $8^{\mathrm{a}}$ ed. Madrid: Popular.

Comité Consultor de Turismo de Loreto (200I). Problemática del Sector Turismo. Región Loreto. Mecanuscrito. lquitos: CCTL.

Croall, Jonathan (1995). Preserve or destroy. Tourism and the environment. Londres: Calouste Gulbenkian Foundation.

González Herrera, Manuel (2000). Estrategia para la oficina de asuntos ambientales de la municipalidad provincial de Maynas. Mecanuscrito. Iquitos.

(200I). Programa Integral de Gestión Ambiental Local para el Desarrollo Sostenible. Mecanuscrito. Iquitos.

(2006). Gestión ambiental de los impactos del turismo en espacios geográficos sensibles. Quito:Abya-Yala.

Haulot, Arthur (1991). Turismo social. México:Trillas.

INEI (2003). Compendio estadístico 2003. Lima: Instituto Nacional de Estadística e Informática.

Vidal, María Dolores (2000). Patrimonio cultural y artístico y su puesta en valor 
para el turismo. Material didáctico (inédito). Universidad de Girona. Zambrano, Duval y Carlos Grey (2000). Plan de Desarrollo del Turismo de la Provincia de Maynas. Mecanuscrito. Lima: Escuela Mayor de Gestión Municipal. 


\section{Actualización y capacitación profesional La tarea es permanente}

La Universidad de Quintana Roo extiende sus programas de educación a la sociedad, para elevar la calidad del desempeño profesional y de los servicios que contribuyen al crecimiento de nuestra región.

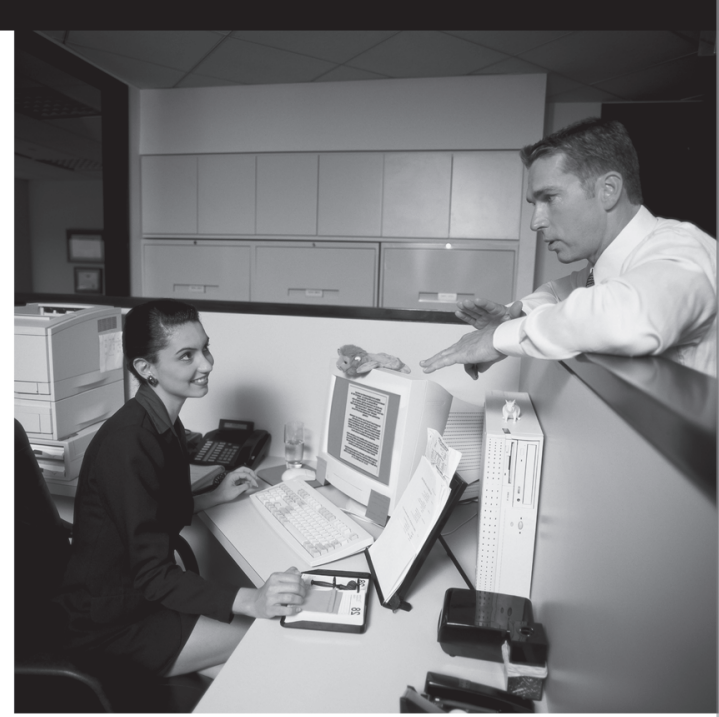

El Centro de Extensión y Servicios pone a su disposición el Programa de Educación Continua, que ofrece capacitación profesional y actualización en:

- Idiomas con certificación internacional

- Alta dirección y recursos humanos

- Administración y turismo

- Empoderamiento para el sector empresarial

- Tecnologías de la información

- Gestión educativa y desarrollo docente

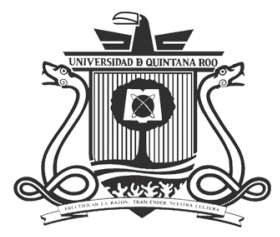

